\title{
How to Improve Information and Knowledge Quality for Business Benefits
}

\author{
Christian Maurer, Markus Steiner, and Reinhard Bernsteiner
}

\begin{abstract}
Knowledge management (KM) has been subject to a lively discussion for several decades. Interest in $\mathrm{KM}$ remains high and it seems that managers and practitioners have started to realize the benefits of KM applications for their businesses. If companies want to generate high quality knowledge from their information, the quality of this information is vital. The paper draws upon the Delone \& McLean information system success model as well as the SECI model and suggests a relationship between the two being mediated by information and knowledge quality. Improvements in information and knowledge quality originating from a SECI-like process interplay with the information system success model. Gaining a cutting edge out of the right interplay between processes and the right inset of a company's knowledge quality could be related to cash-benefits.

To put the proposed theory to test, a SECI-like process is implemented. Drawing upon production employees, the authors externalize knowledge by using interviews. The outcome of the interviews is used within an information system to start a continuous improvement process for information and knowledge quality. Results of a questionnaire deployed after several weeks of exposure suggest a positive response of employees towards the implemented process.
\end{abstract}

Index Terms-Knowledge management, SECI model, Delone \& McLean information system-success model, knowledge quality.

\section{INTRODUCTION}

Knowledge Management (KM), being an outgrowth of the resource based view [1] of the company, can increase the company's ability to compete [2]. Sufficiently high levels of organizational knowledge quality improve management performance [3]. Therefore, one can justify the interest of managers in this field. KM is therefore an important topic for any organization and information can be considered as one of the building blocks that lead to knowledge.

However, it has been argued that there is a lack of studies explaining the actual connection between organizational performance and KM [4]. This might be explained by the fact, that there is a vanishing number of concise approaches to implementing KM in business processes.

The theoretical background section of this paper strives to explain the idea of the authors based on previous research from the field. The proposed process to improve information and knowledge quality will be explained along with the research question. An explanation of the methodology used in each part of the contribution follows. The results section summarizes the findings and answers the research question posed before. A discussion finalizes this contribution along

Manuscript received February 2, 2014; revised April 25, 2014

The authors are with the Management Center Innsbruck, Innsbruck, Austria (e-mail: mc7092@mci4me.at, ma.steiner@mci4me.at, reinhardchristian.bernsteiner@mci.edu). with ideas for further research.

Since the data used in this paper provides a potential competitive advantage to the respective organizations, the authors must not include company names, interview partners as well as any company specific information.

\section{THEORETICAL BACKGROUND}

\section{A. Data, Information and Knowledge}

During the last decades, various definitions of data, information and knowledge have been coined. In 2006 the five-tier knowledge management (KM) hierarchy was published [5]. The authors argue that a consensus exists that "data are discrete facts, but after that, consensus is lacking" [5]. They furthermore state, that individual knowledge as well as facts are merely building blocks to reach the "exploitation of knowledge-based resources" [5]. Building on this hierarchy, one could argue, that improving individual knowledge could improve facts as well, since facts and their interpretation build upon individual knowledge. This corresponds closely to what can be witnessed in daily life: As people get more knowledgeable about a certain domain, they become better at extracting facts or details from a stream of information. For example, a student, not having much knowledge about the domain of knowledge management might not be able to elicit the same amount of information from an information stream (for example: a conference contribution) as her professor might.

Similarly, Peter Drucker argued that information is created from data by using knowledge [6]. Therefore, if one wishes to improve information quality either data quality or knowledge quality could be improved, in order to generate better information. Based on this definition, data quality and knowledge quality serve the same purpose, which is to improve information quality. One might therefore argue that information quality increases with knowledge, but knowledge draws upon information. This suggests that information and knowledge are very much intertwined and dependent upon each other.

Those two extracts from literature show that the more traditional view of data, information and knowledge as a hierarchy of concepts is challenged. The authors adopt the view that information quality and knowledge quality are related concepts - it is likely that an improvement in one area leads to improvements in the other. It is argued that new knowledge about a certain topic leads to better information as proponents get more sensitive to the measurement of facts in this domain. This notion is related to the absorptive capacity of the firm, in which companies have to have some related, prior knowledge in order to assimilate new knowledge [7].

Furthermore, the use of knowledge creates a reinforcing 
process: The more knowledge being used, the more is created [8]. This is similar to the notion of some authors who state, that a self-reinforcing cycle is created, since knowledge becomes more valuable as it is used [9]. Clearly, those statements indicate that knowledge management is an important area for every firm. Nevertheless, the statements also show that in an economy, where knowledge is held by individuals, and companies depend upon this knowledge, the typical shareholder value approach becomes more and more challenged [1].

\section{B. Delone and McLean IS Success Model}

William De Lone and Ephraim McLean developed the Information System Success Model. They state that the success of an Information System is a multidimensional and interdependent entity [10]. In other words, this means that more than just one factor is responsible for the success of an Information System and furthermore, all of the factors are connected with each other. Therefore, information quality as well as service and systems quality are crucial for business success and influence the users' intention to use the Information System [10]. By some intermediate factors, those quality measures furthermore influence net benefits for the users.

Data quality is an interesting and important aspect of all of the three layers above, because it directly influences the service quality layer, the information quality layer and the system quality layer. Data quality has far reaching consequences for every organization [11]. The authors [10] also include the aspect of 'quality' within their model.

\section{The SECI Model}

In his seminal work, Nonaka (one year later Nonaka and Takeuchi) published the SECI process as a model to explain knowledge creation [12], [13]. Nonaka argues that the process takes the form of a spiral and that there are "four different patterns of interaction between tacit and explicit knowledge" [12]. Furthermore he states that out of those patterns new knowledge can be created from existing knowledge [12]. For the scope of this paper it is important to stress that Nonaka describes his process as a spiral like shape, where tacit and explicit knowledge continuously interact with each other [12]. In later work the concepts are advanced even further and the SECI process is embedded in a holistic view together with ba (i.e. 'place' [14]) and knowledge assets [14]. For more than a decade, the SECI model has remained one of the main streams of research in knowledge management, which indicates its importance for the whole field. However, for the scope of this contribution it is merely important to adopt the view that the SECI process can be used to describe knowledge creation [15].

\section{Proposed Process TO IMPROVE INFORMATION AND KNOWLEDGE QUALITY}

The SECI process is one way to explain the creation of knowledge. However, it does not guide practitioners through the steps of implementing concise KM applications and therefore lacks to offer a step-by-step model to improve information and knowledge quality. Also, it was argued that explicit knowledge (or at least the chance to share the tacit knowledge) offers greater value to a company than tacit knowledge being embodied in individuals [16]. The authors therefore present the following process as a solution for a knowledge sharing process to improve information and knowledge quality.

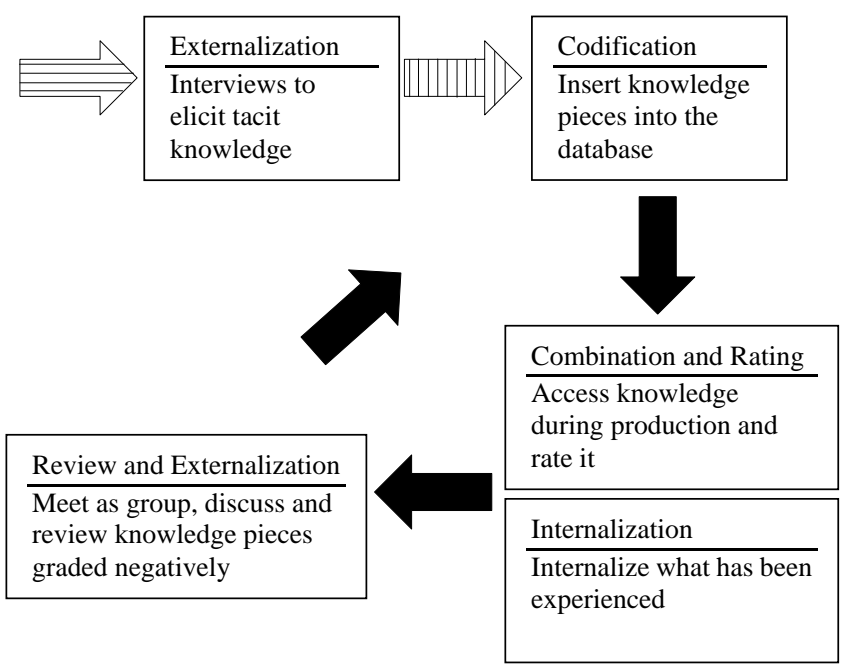

Fig. 1. The proposed process for improving information and knowledge quality, based on the SECI process.

The process starts at the lengthwise striped arrow. Here, the externalization phase is triggered. Within this step the knowledgeable subjects are interviewed about a certain domain. Whether structured, unstructured or semi-structured interviews are used, depends on the exact characteristics of the knowledge to be elicited as well as the subjects themselves.

The interviews are then scanned for 'knowledge pieces'. A knowledge piece is every fact that conveys some kind of if-then relationship, for example, 'if surface of product is hazy, then reduce temperature to X degree'. Those pieces of knowledge are scanned for additional information that interviewees have added, for example 'but this only applies if we produce type A materials'. This additional information is added to the knowledge piece as meta data.

The knowledge piece together with its meta data provides enough contextual information to infer from a situation in the production process which knowledge piece could be used. From an IT perspective this means that the meta data allows for retrieving pieces of knowledge from a database where the meta data serves as selection criteria (typically the WHERE clause of a SQL statement).

The knowledge pieces are used in the production environment and presented by an IS to the machine operator. For every order being produced, the machine operator is able to click onto the order in a digital order list and receive all pieces of knowledge that apply to this order, based on the meta data stored along with the knowledge pieces. The machine operator then sifts through the pieces of knowledge and compares them with the current production situation. In case the knowledge piece does state something correct, the machine operator rates it positively $(+1)$ and in case the knowledge piece does not apply to the current situation, the machine operator rates the knowledge piece negatively $(-1)$. The machine operator might also see a knowledge piece he does not know and try to see if it works (subsequently he also 
rates the knowledge piece +1 ) or discovers that it does not work (and subsequently rates it -1 ). Within this step the machine operator emerges his tacit knowledge and compares it with the available explicit knowledge from the IS in order to combine it.

The experience the machine operator has collected (knowledge piece has worked or has not worked) is internalized by the individual machine operator ("up until now I have always done $\mathrm{X}$ in this situation, now I see that $\mathrm{Y}$ works better'). Within this step, the internalization phase of the SECI model takes place.

After several weeks, the machine operators meet as a group and discuss the negatively rated knowledge pieces (for example knowledge piece $X$ was rated negatively 9 times). Those knowledge pieces either need refinement or revision. This revision is discussed in a group setting, where the employees' individual knowledge is externalized by a discussion, codified (with new meta-data) and inserted into the database again. Here, the process (filled arrows) starts over.

For the scope of this paper, the authors will adopt the view, that information is the basis for knowledge to be built, but once knowledge exists it can be used to verify information and improve it. Improved knowledge in, for example, a manufacturing process would be likely to enable staff to generate more concise information, interpret it more accurately and therefore improve information quality and also pavethe way for a better quality of knowledge. Hence it can be argued that a platform which helps individuals to improve knowledge about a domain also has positive impacts on the ability to generate high quality information. This leads to the research question in this paper:

"Does the proposed process represent a viable solution to improve information and knowledge quality to increase business benefits?"

\section{Methodology}

Within section A the organizational setting in which the research has been conducted will be explained. Within section $\mathrm{B}$ the interviews have been conducted to prove the importance of information quality for business processes. The subsequent sections describe how the knowledge for the process was externalized (C), how the IS to support the proposed process was developed (D) and the questionnaire which was used to capture the opinions employees have about the application (E). The questionnaire serves as proof that the results obtained from the interviews are viable and not misinterpreted. Therefore, the questionnaire serves as a triangulation method in order to verify the usefulness of the externalized knowledge pieces and the proposed process. Only a sufficient number of knowledge pieces paired with positive feedback from employees will indicate the successful implementation of the process.

\section{A. Organizational Setting}

For the interviews in section A, CIOs, a CEO, university Information System-Professors and responsible employees for implementing IT-projects in various companies have been interviewed to determine the prime role of data quality.
Those interview partners have shared their knowledge to provide a qualitative measure on how important data quality, especially when it comes to Information Systems, is for an organization.

In section $\mathrm{B}$, production employees have externalized their knowledge in interviews. All production employees work for one manufacturing company in Austria. Starting from section $\mathrm{C}$, the authors will describe a process, which was implemented in one of the company's core production processes at the headquarters.

\section{B. Interviews - Importance of Data Quality}

For the interviews regarding the importance of data quality, the qualitative approach of the content analysis was used. Schilling mentions that establishing categories within the analysis phase of the interviews is crucial [17]. Schilling [17] and Neuendorf [18] mention that within the deductive approach of qualitative content analysis, the research question, as well as the hypotheses is defined before the data collection took place. Therefore it must be mentioned that the deductive approach of the qualitative content analysis was used in this research paper.

\section{Interviews - Knowledge Elicitation}

For eliciting knowledge from production employees, again interviews were used. The authors decided to use interviews, since they are a way of giving respondents the feeling that their answers will not be sanctioned at a later stage [19]. However, using interviews as a way to elicit knowledge can pose threats too. In some cultures preventing the interviewer from losing his face is more important to the interviewee than actually telling the truth [19]. However, since the interviewer was part of the same culture as the respondents, the risk of inter-cultural differences is low. Furthermore, the authors acknowledge that in interviews it can be hard to ensure that the interviewer and the interviewee speak the same language [19]. However, during the interviews the interviewees asked for clarification as some questions were not entirely clear to them. Therefore the authors argue that the negative influence of this issue was quite small, if at all present.

The usage of interviews within the knowledge elicitation slightly differs from the interviews used for proving the importance of data quality. The prime reason for this is that the outcome of the two interviews is different. Within the data quality interviews, the aim was to explore whether data quality is considered important or not. Within the knowledge elicitation interviews the aim was to extract very concise pieces of knowledge in a format of 'if-then' relationships, which could then be used in a database to retrieve pieces of knowledge via SQL statements.

The authors state that in this section other methodologies for externalizing tacit knowledge could be used. However, since the above mentioned constraints of interviews do not really apply in this setting, the usage of interviews as a technique for explicating tacit knowledge appears to be viable.

Within this setting, the interviews were held in an open style. Since interviews are limited in duration and scope, it was important to externalize knowledge relevant for a large number of produced materials. Therefore historical production data was analyzed prior to the interviews and scanned for the most relevant materials. By applying a cluster 
analysis for key production parameters the interviewer knew which materials are especially relevant for knowledge externalization. Those materials have been used in the interviews as a prime reference for the questions in order to maximize the outcome of the interviews.

\section{System Development}

The proposed process in Fig. 1 requires Information System support in order to be executed as explained. This Information System was developed by one of the authors and should be explained to the reader. The process was implemented based on the company's SAP system. An existing solution was extended to offer the necessary screens to employees working in the production process. The created solution can be seen as a collaboration tool according to [20], since it eases communication and also coordination to a certain extent (by mediating information concerning successfulness of applying a knowledge piece) between employees. Also, it satisfies some information processing needs, which even more classifies the created solution as a collaboration tool [20].

The authors are aware that certain solutions exist that allow rule-based decision finding, like SAP BRF+. However, this was not a viable solution in this setting as it is used for static rules whereas the application in this setting had to allow for rating of knowledge pieces and corresponding ordering of knowledge hints. Therefore the IT support was achieved by extending an existing application which was used by the machine operators for the quality inspection process. Within the existing application, the machine operator was able to view orders queued for production. The author then developed a backend system based on SAP MII and an Oracle database which delivered the right knowledge hints, which was then integrated into the frontend by the company's head of software development.

It is confirmed that databases are an appropriate vehicle for making tacit knowledge explicit [21]. This enables production employees to retrieve pieces of knowledge and rate it accordingly. Upon the next time the hints for this combination of meta data are retrieved, the hints are ranked from highest to lowest rating. This makes it possible for production employees to read for example, three best production hints (knowledge pieces) on top of the list.

\section{E. Questionnaire}

After deploying the system and monitoring its usage, a survey was conducted to capture the employees' mind about the application. The questionnaire was presented to the employees via a link in the application to allow for easy access. Due to the very small population for this questionnaire, it was not possible to pre-test it with respondents from the later sample. Instead, the questionnaire was verified by review of people with academic backgrounds and the production department's head in the company.

The authors acknowledge that for this questionnaire the most obvious problem was the very small initial population. Nevertheless, since one of the authors conducted the interviews with the employees it seemed inappropriate to conduct a second round of interviews with the same interviewer and interviewees. Basically the authors were afraid that effects similar to the sponsorship effect [19] could arise as the employees already know the interviewer.
Furthermore, an interview held on a personal level, which might be reached at meeting the same person for the second time, might not reveal the accurate truth about people's feeling about the IS so much like an anonymous questionnaire. The respondents might be afraid to confess that they did not use the application in a face-to-face interview. In a questionnaire this effect might be less prevalent. Preston [22] has argued that questionnaires are not well suited for collecting sensitive information. However, within this study, the information captured does not contain sensitive information. Also, Preston [22] states that questionnaires often lead to incomplete responses. However, a panel discussion as suggested by Preston to prevent people from forgetting details [22] does not seem to make sense, as employees were exposed to the questionnaire after $5 \quad 1 / 2$ weeks of working with the application. Therefore it can be assumed that people's memory were quite complete. Also Preston [22] stated that respondents need the necessary knowledge and the information to answer the questionnaire. Since the questionnaire concerns the daily work of the respondents, it can be assumed that they do have the necessary knowledge and information.

\section{RESULTS}

Within the results section the authors present two distinct outcomes. First, the outcome regarding the importance of data quality, especially related to knowledge elicitation, during the implementation of an innovation for an organization, will be explained. Second, the results of the knowledge elicitation, system usage and questionnaire are presented.

\section{A. Interviews - Data Quality}

There is no questioning the fact, as the trend towards the virtual firm has reached all levels of business; the importance of data quality is undeniable. Business processes and information technology must be well-matched and knowledge gained, should be driven to further stages within the company from intern key-users and experts. One expert mentioned within the interview that with the degree of data quality, as well as the engagement of the key-users of their Information Systems of the company's project failed or turned out as success. Thus, the statement of the authors [23], where they are stating that every IT-based innovation for example, an Information System, has radical and subsequent pervasive impact on intern business processes can be supported. Therefore, a radical loss of data quality, which in hindsight is a radical and subsequent pervasive impact for any organization, should be denied, from the expert's point of view. Combining this statement with knowledge elicitation means that there could also be radical and subsequent pervasive impact on a company's internal knowledge management. If knowledge management is concerned, the experts in the interviews point out that, usually tremendous costs are involved for an organization. Due to the people involved, for data quality, template approaches within such an implementation are common in every day's business environment. Bringing up the topic of a template approach, companies can secure that projects which turned out as successes beforehand, are highly like to also turn out as 
successes in the future. The experts point out that data quality requested can be estimated within further projects. Furthermore, it seems even more important that knowledge is secured within an organization during such an implementation phase. Business Processes and Information Technology must be seen as one integral unit, otherwise organizations will face huge problems towards their business processes [24]. In other words, this means that if there is a new Information System within an organization, Business Processes are affected automatically. For the manager involved, this means that both sides have to be adapted and well-matched. Due to the interviewee, just fixing one side is not enough for a high standard of data quality of an Information System.

Experts mention within the interviews, that Business Process Management has to be set up beforehand. Afterwards, challenges towards the introduction of an Information System can be analyzed and handled. Looking at the purpose of an organization, the challenging questions are strategy and data quality. In order to gain competitive advantage, adoptions may be the cutting edge to win the race. Creating something unique and it does not matter whether it is an Information System, or any other product, can help to gain the value of an organization [25]. Therefore, data quality plays a central key role for any organization. Besides data quality, knowledge management is another key-topic within this issue. Nonaka and Toyama [26] state that the creation of knowledge is seen as dialectical process, in which various contradictions are synthesized through dynamic interactions among individuals, the organization and the environment. Interpreting the outcomes of the research, the success of an organization gets influenced heavily by the issue of knowledge management, data management as part of the information management and on the areas linked up with information management (e.g. financial analysis, human resource management, etc.). Key-users as a major part of any organization can also be seen as another influence factor of several IT-based innovation projects. The acceptance of the new system, which is predetermined by the satisfaction and the intention to use, is a major issue within organizations. Therefore, only permitted employees should be privileged to be part of such an implementation-committee, because the creation of knowledge -so to say, an organization's intellectual property - within an organization is a very sensitive topic [27]. The first step for executives of organizations is understanding intern processes [28]. Davenport mentions that many projects fail because of the lack of understanding intern business processes, and therefore intern knowledge Business Processes and parallel operations reflect knowledge. Therefore, transparent processes and transparent decisions of management are success factors within every project [29].

Looking back to the Delone and McLean Information System Success Model, it gets clear, why the success of such an Information System is multidimensional and interdependent. Business Process Management, Technology Acceptance Models and Human Interaction, are just three topics, which play a central role for the success of a system. Besides these three topics, several others are part of the 'multidimensional' factor. Interdependency means that just one factor, e.g. of the factors named above, can decide, whether the project turns out as a failure or success. Therefore it is important to integrate several experts out of different areas, with different knowledge and hands-on experience, e.g. management, finance, information technology, etc. into the project. Creating marvelous business processes and implementing a system within the organization is useless if the acceptance of the key-users is not available. Coming back to multinationals, it seems even more important to secure knowledge gained out of such projects. Even if a project fails, the possibility of analyzing the defective undertaking is given, because knowledge and steps within the project have been recorded.

\section{B. Interviews - Knowledge Elicitation}

In order to elicit knowledge from production employees, 12 interviews were conducted. The interviews have been held on two subsequent days. Machine operators and shift leaders (each being responsible for several machine operators and therefore as knowledgeable as most machine operators in this domain) have been accepted as interview partners. Out of 4 possible rotating shifts 3 are represented in the interviews. All employees who were asked to participate were happy to do so. The author guaranteed anonymity of the results. Out of those interviews, approximately 200 pieces of knowledge were elicited. The knowledge pieces have been taken down with the corresponding meta data and were discussed with the production foreman of the production process. This step of discussing the interview results with the production foreman is not represented in the model in Fig. 1, since it originated from the organizational situation in this setting. In case of this company serving as a research object, it was important to let somebody responsible for production approve the hints to be used by production employees.

The authors state that this step in the end does not change the outcome of the process. If this step would not have been conducted and production hints which represent wrong information would have been deployed, production employees would have had the chance to rate the hints negatively and choose to delete them at the next meeting. However, and this was the main reason for consulting with the production foreman, until then, some production orders would maybe have been produced based on the wrong production hints, leading to excessive production of scrap. Nevertheless, the duration of the interviews and the rich outcome (approx. 200 pieces of knowledge) indicate that the methodology of interviews and eliciting if-then clauses is a viable approach to elicit knowledge from employees in manufacturing processes.

\section{System Usage}

The system was deployed at the end of March 2013 and remained online. Within the following 5 1/2 weeks (until 00:10 on $2^{\text {nd }}$ of May) the system recorded 81 ratings of knowledge pieces. Fig. 2 shows the number of ratings on the corresponding days.

The figure includes two implications. First, it is interesting to see that the ratings have been made during only 9 days. Second, the last ratings were recorded on $17^{\text {th }}$ of April, which means that no more ratings were made in the last 2 weeks since the questionnaire was opened. The authors argue that this could be an indicator for the proper cycle time of the process. 


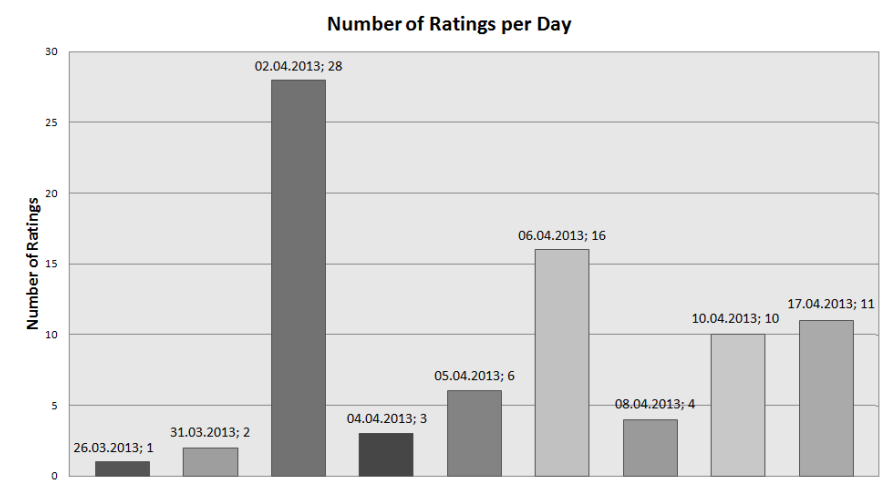

Fig. 2. Number of ratings per day.

\section{Questionnaire}

The questionnaire was available via a hyperlink from the application the employees used. As the whole process was implemented in one production process only, the number of potential respondents was limited to machine operators of the respective process. Therefore the number of potential responses is low, but the rate of return was 5 out of 12 possible responses. The authors are well aware that the presented results do not allow for statistically significant conclusions. Nevertheless, the collected results can still be used to gauge the opinion people have about the implemented application. The respondents have been asked to judge the questions given the availability of proper production hints. The most important answers follow.

It can be concluded that respondents tendentiously rate the production hints as helpful in the way they are implemented currently. This confirms the approach the authors took from an IS perspective. Storing knowledge pieces and retrieving them from a database appears to be a viable approach to present knowledge pieces back to workers during production. Furthermore, employees share the opinion that they can reduce scrap with the utilization of proper production hints. This indicates that the collected hints do indeed represent valuable pieces of knowledge or at least, that machine operators think that they can benefit from the knowledge of their co-workers. This implication is important as it confirms the need for IS like the one presented. Additionally, employees have answered, that improvements materialize due to the utilization of proper production hints. This includes non-material improvements like e.g. reduction in energy use and not merely the reduction of scrap from the previous question. The answer to this question also shows that employees do not perceive the current process as a fully optimized variant, but rather share the opinion that improvements can be made.

The outcomes show a slightly positive image of the application along with business benefits, like the potential to reduce scrap. Summing up the results, the following conclusions seem to be central:

1) The importance of data quality in IS planning and IS at large can be confirmed.

2) Using interviews to elicit knowledge in this setting proved to be a viable approach. The ease in conducting the interviews as well as the amount of elicited knowledge pieces confirmed the authors initial assumptions about the appropriateness of the methodology.
3) The rating of production hints shows that employees do use the application and that the process as such (eliciting interviews and letting employees rate the hints afterwards) works. The time in which ratings have been conducted indicates the proper time frame for the rating process.

4) The questionnaire evaluation (even if it is not statistically significant) shows a tendentiously positive attitude towards the application and its use.

The research question posed in section III can therefore be answered affirmatively. Based on the gathered data the process is a viable solution to increase information and knowledge quality and does, drawing upon the Delone \& McLean IS success model, increase business benefits. Those results are subject to discussion in the next section of this contribution.

\section{DISCUSSION AND FURTHER RESEARCH}

The results of this contribution confirm the importance of data quality and subsequently information and knowledge quality for organizations. The interviews with representatives from the forefront of IT also confirm the necessity and importance of this topic for IS at large, both for academia as well as businesses. Therefore the presented process to improve information and knowledge quality by using IS appears to be a viable approach towards satisfying the need for solutions to remedy missing information or knowledge quality. However, the authors want to make a few qualifications to their findings.

First, the interviews held to confirm the importance of data quality are not representative in terms of criteria for a quantitative study. They are exploratory in nature and therefore could have yielded one-sided results. Nevertheless, the authors consider the results regarding the importance of data quality for businesses and IS as thoroughly confirmed by previous research. Furthermore, the proposed process was set up for a very specific setting within one plant of a manufacturing company. The approach as such might have yielded promising results, but may not necessarily work in other settings as well. Therefore further research is needed in order to apply the same process in different settings. Also, the system usage as such might decline with time, resulting in a problem known from virtual team management, where the problem actually is to integrate a certain technology into the work practices [30]. This is probably the biggest risk the process faces - people might not see the potential of the IS and subsequently not adopt it on a broader scale or discontinue using the system. Furthermore, ratings of knowledge hints have not been made for the last 2 weeks before the system was evaluated. This might indicate that the best cycle time of the process is around 3 weeks. This means after 3 weeks the ratings should be reviewed in order to prevent employees from losing the interest in the application.

The process as such is a potential object for longitudinal research, which was also demanded in earlier research conducted in this field. Within the scope of this contribution, it was not possible to conduct such a study. However, scholars should be motivated to pick up the presented results and evaluate them in a longitudinal setting.

Despite the constraints mentioned, the authors are 
convinced that the findings of this contribution can help practitioners to implement their KM applications.

\section{REFERENCES}

[1] R. Grant, "Toward a knowledge-based theory of the firm," Strategic Management Journal, Winter Special Issue, vol. 17, pp. 109-122, 1996.

[2] M. Zack, "Developing a knowledge strategy," California Management Review, vol. 41, no. 3, pp. 124-145, Spring 1999.

[3] K. Lee, S. Lee, and I. Kang, "KMPI: measuring knowledge management performance," Information and Management, vol. 42, pp. 469-482, March 2005.

[4] T. Andreeva and A. Kianto, "Does knowledge management really matter? Linking knowledge management practices, competitiveness and economic performance," Journal of Knowledge Management, vol. 16, no. 4, pp. 617-636, 2012.

[5] R. Hicks, R. Dattero, and S. Galup, "The five-tier knowledge management hierarchy," Journal of Knowledge Management, vol. 10 , no. 1, pp. 19-31, 2006.

[6] P. Drucker, "The coming of the new organization," in Harvard Business Review on Knowledge Management, Harvard Business School Press, Boston, MA: Harvard Business School Press, 1998, pp. $1-19$.

[7] W. Cohen and D. Levinthal, "Absorptive capacity: A new perspective on learning and innovation," Administrative Science Quarterly, vol. 35, no. 1, pp. 128-152, March 1990.

[8] M. Augier and M. Vendelø, "Networks, cognition and management of tacit knowledge," Journal of Knowledge Management, vol. 3, no. 4, pp. 252-261, 1999

[9] H. Zaim, E. Tatoglu, and S. Zaim, "Performance of knowledge management practices: a causal analysis," Journal of Knowledge Management, vol. 11, no. 6, pp. 54-67, 2007.

[10] S. Petter, P. Delone, and E. McLean, "Measuring information systems success: models, dimensions, measures, and interrelationships," European Journal of Information Systems, vol. 17, pp. 09-30, 2003.

[11] C. Battini and M. Scannapieco, Data Quality - Concepts, Methodologies and Techniques, Berlin-Heidelberg, GER.: Springer-Verlag, 2006.

[12] I. Nonaka, "A Dynamic Theory of Organizational Knowledge Creation," Organization Science, vol. 5, no. 1, pp. 14-37, February 1994.

[13] I. Nonaka and H. Takeuchi, The Knowledge-Creating Company - How Japanese Companies Create the Dynamics of Innovation, New York: Oxford University Press, 1995.

[14] I. Nonaka, R. Toyama, and N. Konno, "SECI, Ba and Leadership: a unified model of dynamic knowledge creation," Long Range Planning, vol. 33, pp. 5-34, 2000.

[15] B. Choi and H. Lee, "Knowledge management strategy and its link to knowledge creation process," Expert Systems with Applications, vol. 23, no. 3, pp. 173-187, October 2002.

[16] T. H. Herrgard, "Difficulties in diffusion of tacit knowledge in organizations," Journal of Intellectual Capital, vol. 1, no. 4, pp. 357-365, 2000.

[17] J. Schilling, "On the pragmatics of qualitative assessment," European Journal of Psychological Assessment, vol. 22, no. 1, pp. 28-37, 2006.

[18] K. A. Neuendorf, The Content Analysis Guidebook, Thousand Oaks, vol. 7, 2007

[19] A. Diekmann, Empirische Sozialforschung - Grundlagen, Methoden, Anwendungen, Reinbek bei Hamburg, GER.: Rowohlt Taschenbuch Verlag, 2013, pp. 242-470.

[20] I. Zigurs and B. Munkvold, "Collaboration technologies, tasks, and contexts: Evolution and opportunity," in Humancomputer Interaction And Management Information Systems: Foundations., P. Zhang \&D. F. Galletta, Eds. Armonk, NY: M.E. Sharpe, 2006, ch. 7, pp. 143-169.

[21] U. Mulder and A. Whiteley, "Emerging and capturing tacit knowledge: a methodology for a bounded environment," Journal of Knowledge Management, vol. 11, no. 1, pp. 68-83, 2007.
[22] V. Preston, "Questionnaire Survey," International Encyclopedia of Human Geography, pp. 46-52, 2009.

[23] K. Lyytinen and G. Rose, "The disruptive nature of information technology innovations: the case of internet computing in systems development organizations," MIS Quarterly, vol. 27, no. 4, pp 557-595, December 2003.

[24] K. Liu, L. Sun, and K. Bennett, "Co-Design of business and IT systems - Introduction by guest editors," Information Systems Frontiers, vol. 4 no. 3, pp. 251-256, September 2002.

[25] J. Tidd and J. Bessant, Managing Innovation: Integrating Technological, Market And Organizational Change, 4th ed., Chichester, UK: Wiley, 2009.

[26] I. Nonaka and R. Toyama, "The knowledge-creating theory revisited: knowledge creation as a synthesizing process," Knowledge Management Research and Practice, vol. 1, no. 1, pp. 2-10, July 2003.

[27] E. Bertino, L. R. Khan, R. Sandhu, and B. Thuraisingham, "Secure knowledge management: Confidentiality, trust, and privacy," IEEE Transactions on Systems, Man, and Cybernetics - Part A: Systems and Humans, vol. 36, no. 3, pp. 429-438, May 2006.

[28] T. Davenport, Process Innovation: Reengineering Work through Information Technology, Boston: Harvard Business School Press, 1993.

[29] J. Hofmann, IT-Basiertes Innovationsmanagement, Heidelberg: dpunktverlag, 2010.

[30] M. Karoui, A. Grkan, and A. Dudezert, "Virtual team collaboration: A review of literature and perspectives," presented at Sixteenth Americas Conference on Information Systems, Lima, Peru, 2010.

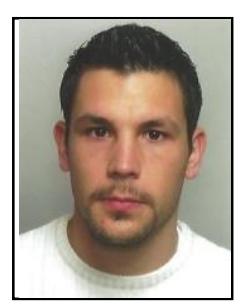

Christian Maurer was born in Hall in Tyrol, Austria in 1986 and obtained a bachelor's and master's degree from Management Center Innsbruck, Austria, in management, communication and IT as well as a bachelor's degree from the same institution in environmental and process engineering.

He has worked as project manager, special needs teacher, software developer and self-employed IT entrepreneur and is currently SAP consultant in Tyrol, Austria.

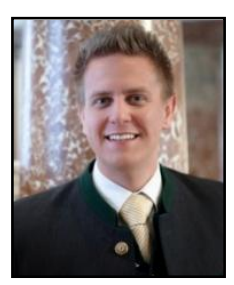

Markus Steiner was born in Mittersill in Salzburg, Austria, in 1987 and obtained a bachelor's and master's degree from Management Center Innsbruck in management, communication \& IT. During his academic path, he was also a student of the University of Wisconsin, Eau-Claire, where he took place in an exchange program, which was called Glob IT. He visited mainly IT and management courses at UWEC in 2010 .

He has worked as executive assistant in several companies, special needs teacher, and is currently employed in a tax consultant office, Prodinger \& Partner, in Zell am See, Austria, where he is advising, analyzing and consulting different companies as a tax consultant aspirant.

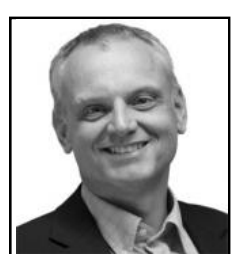

Reinhard Bernsteiner holds degrees in business administration and computer science from Kepler University Linz, Austria and attended postgraduate studies at the Technical University of Vienna, Austria.

He has worked in industry for several years where he gained professional experience in national and international projects in international companies before he returned to academia. Currently, he is professor in the academic department management, communication \& IT at Management Center Innsbruck. 